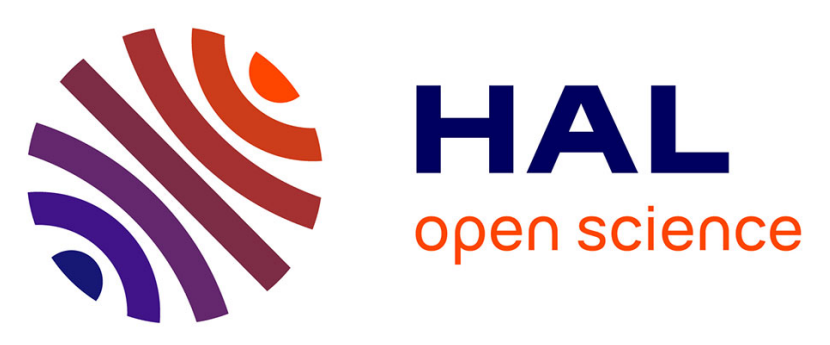

\title{
Numerical and Comparative Study of the Agility of Planar Transmission Lines printed on a Ferroelectric Thin Film
}

\author{
Arnaud-Gides Moussavou, Valérie Bouquet, Ronan Sauleau, Andre Perrin, \\ Maryline Guilloux-Viry, Kouroch Mahdjoubi
}

\section{To cite this version:}

Arnaud-Gides Moussavou, Valérie Bouquet, Ronan Sauleau, Andre Perrin, Maryline Guilloux-Viry, et al.. Numerical and Comparative Study of the Agility of Planar Transmission Lines printed on a Ferroelectric Thin Film. Microwave and Optical Technology Letters, 2007, 49 (2), pp.280 - 285. 10.1002/mop.22106 . hal-00276999

\section{HAL Id: hal-00276999 \\ https://hal.science/hal-00276999}

Submitted on 6 May 2008

HAL is a multi-disciplinary open access archive for the deposit and dissemination of scientific research documents, whether they are published or not. The documents may come from teaching and research institutions in France or abroad, or from public or private research centers.
L'archive ouverte pluridisciplinaire HAL, est destinée au dépôt et à la diffusion de documents scientifiques de niveau recherche, publiés ou non, émanant des établissements d'enseignement et de recherche français ou étrangers, des laboratoires publics ou privés. 


\title{
Numerical and Comparative Study of the Agility of Planar
}

\section{Transmission Lines printed on a Ferroelectric Thin Film}

\author{
A-G. Moussavou ${ }^{(1,2)}$, V. Bouquet ${ }^{(2)}$, R. Sauleau ${ }^{(1)}$, A. Perrin ${ }^{(2)}$, M. Guilloux-Viry ${ }^{(2)}$, K. \\ Mahdjoubi $^{(1)}$
}

\begin{abstract}
In this paper, we report on simulation results at $10 \mathrm{GHz}$ of planar transmission lines (TL) printed on a ferroelectric thin film deposited on sapphire and lanthanum aluminate substrates. The ferroelectric film permittivity is supposed to vary from 700 to 500 . First, the main properties of microstrip (MS), coplanar waveguide (CPW) and coplanar strips (CS) namely their effective permittivity, characteristic impedance and insertion loss are computed as a function of the physical and electrical parameters. Then their tunability and figure of merit are defined and compared. CPW and CS lines present a tunability $\left(\Delta \varepsilon_{\text {eff }} / \varepsilon_{\text {eff_max }}\right)$ of about $16 \%$ for a gap value $\mathrm{g}=30 \mu \mathrm{m}$. The MS lines show a much less tenability of $2 \%$. Moreover, the figure of merit of CPW and CS configurations are of 6.3 and $12.2 \% / \mathrm{dB}$ for a gap value of $30 \mu \mathrm{m}$, respectively. By increasing the gap, these figures of merit can be improved up to the limiting values of 8.7 and $15.4 \% / \mathrm{dB}$, respectively.
\end{abstract}


Index terms: Ferroelectric thin films, Planar transmission lines, Tunability, $\mathrm{KTa}_{\mathrm{x}} \mathrm{Nb}_{1-\mathrm{x}} \mathrm{O}_{3}, \mathrm{Ba}_{\mathrm{x}} \mathrm{Sr}_{1-\mathrm{x}} \mathrm{TiO}_{3}$

\section{Author's affiliations:}

(1) IETR (Institut d'Electronique et de Télécommunications de Rennes), UMR CNRS 6164, www.ietr.org, Université de Rennes 1, Campus de Beaulieu, Bât. 11D, Avenue du Général Leclerc, 35042 Rennes cedex, France.

(2) Unité Sciences Chimiques de Rennes, UMR CNRS 6226 CNRS/Université de Rennes 1, Campus de Beaulieu, Bât. 10A, Avenue du Général Leclerc, 35042 Rennes cedex, France.

\section{Corresponding author:}

Arnaud-Gides Moussavou

Université de Rennes 1

Institut d'Electronique et de Télécommunications de Rennes (IETR)

Groupe Antennes \& Hyperfréquences

Bât 11 D

Campus de Beaulieu

Avenue du Général Leclerc

35042 RENNES Cedex

FRANCE

Phone: + (33) 2. 23.23.57.70

Fax: + (33) 2. 23.23.69.69

Email: arnaud-gides.moussavou@univ-rennes1.fr 


\section{INTRODUCTION}

The rapid development of microwave applications in general public telecommunications has led to a growing interest in tunable devices operating in the $\mathrm{GHz}$ band. Several solutions have been investigated to obtain tunability: (i) integration or mounting of lumped elements (FET transistors, p.i.n and varactor diodes...) or Micro-Electro-Mechanical Systems (MEMS), or (ii) use of agile materials. Among agile materials, ferroelectrics are of particular interest. These materials provide the possibility of tuning due to the electric field dependence of their dielectric permittivity. Moreover, ferroelectric thin films can easily be integrated within planar circuits.

Several ferroelectric devices such as phase shifters [1-3], phased array antenna [4], resonators and filters [5], varactors [6, 7], electromagnetic bandgap structures and metamaterials [8, 9] were designed and realized. Nevertheless none of these contributions investigates and compares the basic properties of printed transmission lines (effective permittivity, characteristic impedance, insertion loss, figure of merit) as a function of the permittivity of the ferroelectric thin films, although these data are of uppermost importance for the design of tunable planar circuits.

Therefore the aim of our work is twofold: (i) analysis of the potential tunability of standard transmission lines, and (ii) determination of the best configuration in terms of loss and tunability. Such data are very useful from an engineering point of view. Here the tunable range of the ferroelectric film permittivity (at room temperature) was chosen to vary between 700 at zero DC-bias field and 500 at moderated field $[10,11]$. These values correspond to ferroelectric materials belonging to $\mathrm{KTa}_{\mathrm{x}} \mathrm{Nb}_{1-\mathrm{x}} \mathrm{O}_{3}$ (KTN) or $\mathrm{Ba}_{\mathrm{x}} \mathrm{Sr}_{1-\mathrm{x}} \mathrm{TiO}_{3}$ (BST) families. Whereas there is a plethora of studies using BST materials, only few papers report on KTN materials, although prior works $[12,13]$ have highlighted the promising performance of the latter (significant agility and reduced loss) . 
Three categories of multilayer transmission lines (TL) are compared and discussed at $10 \mathrm{GHz}$ (Fig.1): microstrip lines (MS), coplanar waveguides (CPW), coplanar strips (CS). These lines are printed on a dielectric substrate $\left(\varepsilon_{\mathrm{r}}, \tan \delta\right)$ of thickness h. The substrates retained in our paper are single crystal of $\mathrm{Al}_{2} \mathrm{O}_{3}$ (sapphire, $\mathrm{h}=500 \mu \mathrm{m}, \varepsilon_{\mathrm{r}}=10$ ) and Lanthanum Aluminate $\left(\mathrm{LaAlO}_{3}, \mathrm{~h}=500 \mu \mathrm{m}, \varepsilon_{\mathrm{r}}=24\right)$. These materials are usually used for the growth of KTN or BST films. The thicknesses of the ferroelectric $\left(\varepsilon_{\mathrm{rf}}, \tan \delta_{\mathrm{f}}\right)$ and metallic conductors are labelled $\mathrm{h}_{\mathrm{f}}$ and $\mathrm{t}$, respectively. In this work, the tunable TL have been simulated using an 3-D commercial electromagnetic tools (Ansoft HFSS). The results obtained by HFSS have been validated by comparing them with data obtained analytically or by other simulators.

This paper is organized as follows. In section II, we investigate and discuss the tunability of various TL as a function of their characteristic impedance $\left(Z_{c}\right)$, supporting substrate and gap dimensions (h \& g) for the uni-planar structures. Their insertion loss and figure of merit are compared in section III. Finally conclusions are drawn in section IV.

\section{Tunability OF Planar transmission lines}

The electrical characteristics of the TL represented in Fig.1 (characteristic impedance $Z_{c}$, propagation constant $\gamma$ ) can be varied due to the non-linear bias electric field dependence of the dielectric permittivity of the ferroelectric film. Depending on the studied device, several definitions are available in the literature for the "tunability" $[1,5,6]$. In this work we adopt the following definition for the tunability $T$ of planar TL:

$$
T=\text { Tunability }(\%)=\frac{\varepsilon_{\text {eff } \max }-\varepsilon_{\text {eff } \min }}{\varepsilon_{\text {eff } \max }} \times 100
$$

where $\varepsilon_{\mathrm{eff} \text { max }}$ and $\varepsilon_{\mathrm{eff} \text { min }}$ are the maximum and minimum effective permittivity of the line, respectively. In this section, the dielectric and metallic losses are not taken into account. 


\section{1 - Influence of the line configurations}

We compare the tunability of the three types of TL (Fig.1) at $10 \mathrm{GHz}$. These lines are printed on sapphire substrate coated with KTN films $\left(\mathrm{h}_{\mathrm{f}}=0.5 \mu \mathrm{m}, 500<\varepsilon_{\mathrm{rf}}<700\right)$. Targeting a characteristic impedance $Z_{\mathrm{c}}=50 \Omega$ for an average value of the ferroelectric permittivity $\varepsilon_{\mathrm{rf}}=$ 600, the TL dimensions become: $\mathrm{a}-\mathrm{MS}$ TL) conductor width $\mathrm{w}=436 \mu \mathrm{m} ; \mathbf{b}-\mathrm{CPW}) \mathrm{w}=18$ $\mu \mathrm{m}$, gap width $\mathrm{g}=30 \mu \mathrm{m} ; \mathbf{c}-\mathrm{CS}$ TL) $\mathrm{w}=310 \mu \mathrm{m}, \mathrm{g}=30 \mu \mathrm{m}$. The gap width is maintained identical for CPW and CS configurations because it determines the DC-bias electric field corresponding to the tunable range of the ferroelectric material.

The variations of $Z_{c}$ and $\varepsilon_{\text {eff }}$ versus the ferroelectric permittivity are represented in Fig. 2-(a) and (b). Fig. 2-(a) shows that, for all transmission lines, the impedance variations remain relatively small (less than $\pm 2.5 \Omega$ around $50 \Omega$ ). In particular for the MS line, the relative variation of $\mathrm{Z}_{\mathrm{c}}$ is negligible (less than $1 \%$ ); but the counterpart is a much lower relative variation of the effective permittivity $\left(7.46<\varepsilon_{\text {eff }}<7.62\right.$ and $T=2 \%$ for the MS line) compared to the other two configurations $(T=16 \%)$. Indeed, for the uni-planar configurations (CPW and CS), the RF electric field lines are concentrated within the gaps, whereas for the MS structure, they are mainly located in the substrate. In addition, as the magnitude of the DC-bias electric field is conversely proportional to the gap width, uni-planar configurations present roughly the same value of tunability. Finally, we can note that the average effective permittivity of the CPW TL $\left(\varepsilon_{\mathrm{eff}}=14.3\right)$ is higher than that of the CS TL $\left(\varepsilon_{\mathrm{eff}}=8.5\right)$. This can be explained by the ratio of their main conductors' width $\left(\mathrm{w}_{\mathrm{cpw}} / \mathrm{w}_{\mathrm{cs}}=\right.$ $0.058)$

\section{2 - Influence of the characteristic impedance}

For each TL configuration, we investigated the variation of the tunability at $10 \mathrm{GHz}$ for various values of $Z_{c}\left(40,50\right.$ and $60 \Omega$ for $\left.\varepsilon_{\mathrm{rf}}=600\right)$. The dimensions of lines on a sapphire substrate are given in Fig.3. For all configurations, $\mathrm{Z}_{\mathrm{c}}$ is controlled by the conductor widths. 
The simulation results given in Fig. 3 demonstrate that for MS and CS configurations, the tunability is almost constant $\left(\sim 2 \%\right.$ and $15.2 \%$, respectively) when $\mathrm{Z}_{\mathrm{c}}$ increases from 40 to 60 $\Omega$. The most promising results concern CPW transmission line for which the tunability increases by $20 \%$ compared to its average value $\left(\mathrm{T}=15.1 \%\right.$ for $\mathrm{Z}_{\mathrm{c}}=40 \Omega$ and $\mathrm{T}=18.3 \%$ for $Z_{c}=60 \Omega$ ). This observation shows that, the tunability of CPW TL can be increased significantly by choosing high impedance lines.

\section{3 - Influence of the substrate's permittivity}

In this section we determine the influence of the supporting substrate on the tunability at 10 GHz. Two substrates are compared: (i) Sapphire: $\varepsilon_{\mathrm{r}}=10, \mathrm{~h}=500 \mu \mathrm{m}$; (ii) Lanthanum aluminate $\left(\mathrm{LaAlO}_{3}\right): \varepsilon_{\mathrm{r}}=24, \mathrm{~h}=500 \mu \mathrm{m}$. MS, CPW and CS lines were designed to be matched at $50 \Omega$ for $\varepsilon_{\mathrm{rf}}=600$. The numerical results given in Fig.4 show that, for a given type of line, TL printed on $\mathrm{LaAlO}_{3}$ substrates are less tunable that those on sapphire substrate. This decrease is quite important for uni-planar configurations, $23.5 \%$ for the CPW structure (from $16.6 \%$ on sapphire to $12.7 \%$ on LAO) and $19 \%$ for the CS configuration (from $15.2 \%$ on sapphire to $12.3 \%$ on LAO). This is due to the relatively high permittivity of LAO $\left(\varepsilon_{\mathrm{r}}=24\right)$ compared to sapphire $\left(\varepsilon_{\mathrm{r}}=10\right)$ which leads to a less effective concentration of the electric field in the ferroelectric layer.

\section{4 - Influence of the gap width}

For the uni-planar configurations (CS and CPW), we have studied the variation of the tunability at $10 \mathrm{GHz}$ as a function of the gap width $\mathrm{g}$. We assume that the TL are printed on sapphire substrates. The widths of the main conductors are given in section 2.1. The corresponding variations of $\mathrm{T}$ are represented in Fig.5. These results confirm that $\mathrm{T}$ increases as $g$ decreases. Indeed, reducing the gap width leads to a more intense microwave electric field and thus an enhanced tunability. Moreover, the tunability of CPW is approximately $2 \%$ higher than that of CS. Simulations have shown that, for CPW lines with a constant value of 
gap, a much wide main conductor (i.e lower $\mathrm{Z}_{\mathrm{c}}$ ) led to a slight decrease of the tunability, as seen in the section 2.2. Finally, we can note that when the gap width decreases (whatever the width of the main conductor is), the tunability of uni-planar lines tends to a limiting value which depends on the relative tuning range of the ferroelectric thin film $\left(\mathrm{T}_{\text {ferro }}=(700\right.$ $500) / 700=28.6 \%)$

\section{INSERTION LOSS AND FIGURE OF MERIT}

The comparative study of different configurations of TL requires determining their insertion loss that is a key parameter when designing tunable devices. In this Section we first investigate the variations of the insertion loss at $10 \mathrm{GHz}$ as a function of the ferroelectric loss $\operatorname{tangent} \tan \boldsymbol{\delta}_{\mathbf{f}}$ and the gap width $\mathbf{g}$ for uni-planar configurations. Then we compare the global performance of the lines by defining their figure of merit. We assume that the metallic conductors are Aluminium $\left(\sigma=3.8 \times 10^{7} \mathrm{~S} / \mathrm{m}, \mathrm{t}=2 \mu \mathrm{m}\right)$ and that they are printed on ferroelectric material $\left(\tan \delta_{\mathrm{f}}\right)$ coated on sapphire $\left(\varepsilon_{\mathrm{r}}=10, \tan \delta=10^{-4}\right)$.

\section{1 - Influence of the ferroelectric loss tangent $\tan \delta_{\mathrm{f}}$ on TL insertion losses}

The dimensions (w, g) of the three lines are the same as those given in Fig. 2. Here we have changed the ferroelectric thin film $\tan \delta_{\mathrm{f}}$ from $10^{-4}$ to 0.5 in order to study the variations of the TL insertion loss. Fig.6 confirms that the overall loss increases exponentially with $\tan \delta_{\mathrm{f}}$. In the MS case, the electric field is mainly concentrated in the substrate. Thus the ferroelectric losses compared to the total losses are less important than for uni-planar configurations and insertion losses remain relatively low (lower than $1.2 \mathrm{~dB} / \mathrm{cm}$ ). For the uni-planar configurations, a value of $\tan \delta_{\mathrm{f}}$ smaller than $10^{-2}$ corresponds to constant insertion loss $\mathrm{t}$ : conductor losses are predominant. As $\tan \delta_{\mathrm{f}}$ becomes higher than $10^{-1}$, the insertion loss becomes crippling. For example, for a loss tangent of 0.5 it becomes higher than $6 \mathrm{~dB} / \mathrm{cm}$. In this case, the ferroelectric losses are predominant. 
Fig.7-(a) and Fig.7-(b) show the individual contributions of metallic, ferroelectric and dielectric losses for two values of $\tan \delta_{\mathrm{f}}\left(10^{-3}\right.$ and $\left.10^{-1}\right)$, respectively. These two figures highlight several observations:

Dielectric loss in the substrate: These losses are small for all configurations (lower than 0.2 $\mathrm{dB} / \mathrm{cm}$ ). However, due to the electric field pattern, the MS line has more substrate's loss $(0.16 \mathrm{~dB} / \mathrm{cm})$ compared to uni-planar configurations $(\sim 0.1 \mathrm{~dB} / \mathrm{cm})$.

Dielectric loss in the ferroelectric thin film: For $\tan \delta_{\mathrm{f}} \sim 10^{-3}$, the ferroelectric losses are negligible $(<0.05 \mathrm{~dB} / \mathrm{cm})$ in the case of MS line and low for uni-planar lines $(0.1 \mathrm{~dB} / \mathrm{cm})$. When $\tan \delta_{\mathrm{f}}$ is multiplied by a factor $100\left(\tan \delta_{\mathrm{f}} \sim 10^{-1}\right)$, ferroelectric losses increase rapidly (0.3, 2.26 and $1.28 \mathrm{~dB} / \mathrm{cm}$ for MS, CPW and CS lines, respectively). These losses represent for each line, more than $60 \%$ of the global insertion loss. Moreover, the concentration of the electric field in both gaps rather than in only one gap, explains why ferroelectric losses in CPW are larger than in CS.

Metallic loss: They are related to the inverse of the width of the main conductor. Thus, the CPW has the most important conductor loss $(1.42 \mathrm{~dB} / \mathrm{cm})$ and the MS line the lowest loss $(0.1 \mathrm{~dB} / \mathrm{cm})$. Conductor loss of CS lines is of the order of $0.5 \mathrm{~dB} / \mathrm{cm}$.

\section{2 - Influence of the gap width in uni-planar configurations}

The variation of the insertion loss is investigated as a function of the gap width $\mathrm{g}$. The widths of main conductors are the same as those given in Section 2.1. According to Fig.9 and as we would expected, the insertion loss increases exponentially when the gap width decreases: the ferroelectric losses increase with the electric field intensity in the gap.

\section{3 - Definition of the figure of merit}

To compare the different types of transmission lines, it is of primary importance to define a new criteria that takes into account both the tunability and the insertion loss (IL) and enables one to make a trade-off in terms between them. Here we define the figure of merit $M$ as 
follows:

$$
M(\% / d B)=\frac{T(\% / \mathrm{cm})}{I L_{\max }(d B / \mathrm{cm})}
$$

where $I L_{\max }$ represents the maximum value of insertion loss obtained when $\varepsilon_{\mathrm{rf}}$ varies. Here $\mathrm{T}$ is tunability determined for the lossless case. Several simulations have shown that the consideration of dielectric and conductor loss modifies only very slightly the value of $\mathrm{T}$.

Fig.9 represents the variation of the figure of merit versus the gap width g. These results show that for $\mathrm{g}<60 \mu \mathrm{m}$, the insertion loss increases more rapidly than the tunability. Thus, the figure of merit decreases with $\mathrm{g}$ and becomes smaller than that of the MS line (for $\mathrm{g}=5 \mu \mathrm{m}$, $\mathrm{M}=3,4.35$ and $5 \% / \mathrm{dB}$ for CPW, CS and MS configurations, respectively). For $\mathrm{g}>60 \mu \mathrm{m}$, $\mathrm{M}$ increases up to a limiting value (15.5 and 8.7 \%/dB for CS and CPW, respectively). This value corresponds to a tunability which decreases as slowly as the insertion loss. Let us note that for our range of gaps, the tunabilities of CPW and CS are of the same order of magnitude (Fig.5), whereas the insertion losses of the CPW configuration are about twice higher than that of the CS structure. Thus the figure of merit of CS is roughly double of that of CPW.

\section{CONCLUSION}

We have compared in this paper the main properties of ferroelectric tunable transmission lines. Their characteristic impedance, tunability, insertion loss and figure of merit have been determined and compared. Our results have highlighted that uni-planar configurations offer a real potential of tunability: CS and CPW are much more tunable $(\mathrm{T} \sim 16 \%$ for $\mathrm{g}=30 \mu \mathrm{m})$ than the MS line $(\mathrm{T} \sim 1.55 \%)$. Then we have shown that the figure of merit of CS configuration $(\mathrm{M}=12.2 \% / \mathrm{dB}$ for $\mathrm{g}=30 \mu \mathrm{m})$ is twice larger than that of $\mathrm{CPW}$ line $(\mathrm{M}=6.3$ $\% / \mathrm{dB}$ for $\mathrm{g}=30 \mu \mathrm{m})$. The numerical results given in this paper are of particular interest as preliminary data when designing reconfigurable devices. We should also mention that a 
technological prerequisite for large integration and development of ferroelectric tunable components is to reach a loss tangent of the order of $10^{-2}$. 


\section{REFERENCES}

[1] W. Kim, M.F. Iskander, C. Tanaka, "High performance low-cost phase-shifter design on ferroelectric materials technology”, Electronics letters, vol. 40, n 21, pp. 1345-1347, Oct. 2004

[2] H. Yoon, K. J. Vinoy, J. K. Abraham, V. K. Varadan, "CPW phase shifter using barium strontium titanate thin film on silicon substrate", IEEE Antennas and Propagation Society International Symposium, Colombus, Ohio, vol. 3, pp. 970- 972, 22-27 June 2003

[3] B. Acikel, T. R. Taylor, P. J. Hansen, J. S. Speck, R. A. York, “A New high performance phase shifter using $\mathrm{Ba}_{\mathrm{x}} \mathrm{Sr}_{1-\mathrm{x}} \mathrm{TiO}_{3}$ thin films", IEEE Microwave and Wireless Components Letters, vol.12, $\mathrm{n}^{\circ} 7$, pp. 237-239, July 2002

[4] P. T. Teo, K. A. Jose, Y. B. Gan, V. K. Varadan, "Beam scanning of array using ferroelectric phase shifters", Electronics letters, vol. 36, n.19, pp. 1624-1626, Sept. 2000

[5] F. A. Miranda, G. Subramanyam, F. W. Van Keuls, R. R. Romanofsky, J. D. Warner, C. H. Mueller, "Design and development of ferroelectric tunable microwave components for Ku-and K-band satellite communications systems", IEEE Transactions on Microwave Theory and Techniques, vol. 48, n 7, pp. 1181-1189, July 2000

[6] K-B. Kim, T-S. Yun, H-S. Kim, R-Y. Kim, H-G. Kim, J-C. Lee, “An interdigital capacitor with high tunability and low loss tangent", $34^{\text {th }}$ European Microwave Conference, Amsterdam, The Netherlands, pp. 161-164, 11-15 Oct. 2004

[7] S. Gevorgian, S. Abadei, H. Berg, H. Jacobson, "MOS varactor with ferroelectric thin films", Microwave Symposium Digest, IEEE MTT-S International, Phoenix, Arizona, vol. 2, pp.1195-1198, 20-25 May 2001

[8] D. Kuylenstierna, G. Subramanyam, A. Vorobiev S. Gevorgian, "Tunable electromagnetic performance of coplanar waveguides periodically loaded by ferroelectric varactors", Microwave and Optical Technology Letters, vol. 39, $\mathrm{n}^{\circ}$ 2, pp. 81-86, Oct. 2003 
[9] D. Kuylenstierna, A. Vorobiev, P. Linnér, S. Gevorgian, "Composite right/left handed transmission line phase shifter using ferroelectric varactors", IEEE Microwave and Wireless Components Letters, vol. 16, n 4, pp. 167-169, April 2006

[10] A. Rousseau, M. Guilloux-Viry, V. Bouquet, A. Perrin, G. Tanné, F. Huret, J. F. Seaux, D. Cros, V. Madrangeas, "Ferroelectric thin films for applications in high frequency range", Ferroelectrics, vol. 316, n 7, pp. 7-12, Dec. 2005

[11] K. Kageyama, A. Sakurai, A. Ando, Y. Sakabe, “Thickness effects on microwave properties of $(\mathrm{Ba}, \mathrm{Sr}) \mathrm{TiO}_{3}$ films for frequency agile technologies", Journal of European Ceramic Society, vol. 26, n 10-11, pp. 1873-1877, 2006

[12] V. Laur, A. Rousseau, G. Tanné, P. Laurent, F. Huret, M. Guilloux-Viry, B. Della, "Tunable microwave components based on $\mathrm{KTa}_{1-\mathrm{x}} \mathrm{Nb}_{\mathrm{x}} \mathrm{O}_{3}$ ferroelectric material", European Microwave Conference, vol. 1, pp. 641-644, Paris, France, 3-7 Oct. 2005

[13] H-J. Bae, D. P. Norton, J. Sigman, L. Boatner, "Low dielectric losses in annealed Tidoped $\mathrm{K}(\mathrm{Ta}, \mathrm{Nb}) \mathrm{O}_{3}$ thin films grown by pulsed laser deposition", Journal of Physics D: Applied Physics, vol. 38, n 9, pp. 1331-1336, May 2005 


\section{FIGURE CAPTIONS}

Fig. 1: Cross-section views of the three configurations of tunable Transmission lines (TL): microstrip line [(a), MS], coplanar waveguide [(b), CPW], coplanar strips [(c), CS]. $\mathrm{w}$ and $\mathrm{g}$ denote the width of the central conductor(s) and the width of the slot between conductors, respectively :

Electric conductors (t);

$\square$ Ferroelectric thin film $\left(\mathrm{h}_{\mathrm{f}}, \varepsilon_{\mathrm{rf}}, \tan \delta_{\mathrm{f}}\right)$;

$\square$ Substrate $\left(h, \varepsilon_{\mathrm{r}}, \tan \delta\right)$.

Fig. 2: Computed values of $\mathrm{Z}_{\mathrm{c}}$ (a) and $\varepsilon_{\text {eff }}$ (b) of MS line, CPW and CS at $10 \mathrm{GHz}$. Conductors and dielectrics are ideal. Substrate: $\varepsilon_{\mathrm{r}}=10, \mathrm{~h}=500 \mu \mathrm{m}$; Ferroelectric film: $500<\varepsilon_{\mathrm{rf}}<700, \mathrm{~h}_{\mathrm{f}}=0.5 \mu \mathrm{m}$.

$-\Theta-M S: w=436 \mu \mathrm{m}$

$\diamond-\mathrm{CPW}: \mathrm{w}=18 \mu \mathrm{m} ; \mathrm{g}=30 \mu \mathrm{m}$;

$-\nabla-\quad C S: w=310 \mu \mathrm{m} ; \mathrm{g}=30 \mu \mathrm{m}$. 
Fig. 3: Variation of the effective permittivity $\varepsilon_{\text {eff }}$ as a function of $\varepsilon_{\mathrm{rf}}$, for three values of $\mathrm{Z}_{\mathrm{c}}$ $\left(\varepsilon_{\mathrm{rf}}=600\right)$ at $10 \mathrm{GHz}$. Conductors and dielectrics are ideal. Substrate: $\varepsilon_{\mathrm{r}}=10, \mathrm{~h}=$ $500 \mu \mathrm{m}$; Ferroelectric film: $500<\varepsilon_{\mathrm{rf}}<700, \mathrm{~h}_{\mathrm{f}}=0.5 \mu \mathrm{m}$.

MS: $\quad \cdots \mathrm{Z}_{\mathrm{c}}\left(\varepsilon_{\mathrm{rf}}=600\right)=40 \Omega, \mathrm{w}=680 \mu \mathrm{m} ;$

$$
\begin{aligned}
& -\Theta-Z_{c}\left(\varepsilon_{\mathrm{rf}}=600\right)=50 \Omega, w=436 \mu \mathrm{m} ; \\
& -\Theta-Z_{c}\left(\varepsilon_{\mathrm{rf}}=600\right)=60 \Omega, w=285 \mu \mathrm{m} ;
\end{aligned}
$$

CPW $: \diamond \mathrm{Z}_{\mathrm{c}}\left(\varepsilon_{\mathrm{rf}}=600\right)=40 \Omega, \mathrm{w}=47 \mu \mathrm{m}, \mathrm{g}=30 \mu \mathrm{m}$;

$$
\mathrm{Z}_{\mathrm{c}}\left(\varepsilon_{\mathrm{rf}}=600\right)=50 \Omega, \mathrm{w}=18 \mu \mathrm{m}, \mathrm{g}=30 \mu \mathrm{m} ;
$$$$
\mathrm{Z}_{\mathrm{c}}\left(\varepsilon_{\mathrm{rf}}=600\right)=60 \Omega, \mathrm{w}=6 \mu \mathrm{m}, \mathrm{g}=30 \mu \mathrm{m}
$$

CS: $\quad \nabla \mathrm{Z}_{\mathrm{c}}\left(\varepsilon_{\mathrm{rf}}=600\right)=40 \Omega, \mathrm{w}=1 \mathrm{~mm}, \mathrm{~g}=30 \mu \mathrm{m}$

$$
\begin{aligned}
& -\nabla-\mathrm{Z}_{\mathrm{c}}\left(\varepsilon_{\mathrm{rf}}=600\right)=50 \Omega, \mathrm{w}=310 \mu \mathrm{m}, \mathrm{g}=30 \mu \mathrm{m} ; \\
& -\nabla \cdot \mathrm{Z}_{\mathrm{c}}\left(\varepsilon_{\mathrm{rf}}=600\right)=60 \Omega, \mathrm{w}=100 \mu \mathrm{m}, \mathrm{g}=30 \mu \mathrm{m} .
\end{aligned}
$$

Fig. 4: Variation of the effective permittivity $\varepsilon_{\mathrm{eff}}$ at $10 \mathrm{GHz}$ of each TL as a function of $\varepsilon_{\mathrm{rf}}$, for two substrates (sapphire and LAO, $\mathrm{h}=500 \mu \mathrm{m}$ ). Conductors and dielectrics are ideal. Ferroelectric film: $500<\varepsilon_{\mathrm{rf}}<700, \mathrm{~h}_{\mathrm{f}}=0.5 \mu \mathrm{m}$.

MS : $\quad \bigcirc / \mathrm{LAO}, \mathrm{w}=140 \mu \mathrm{m} ;$

$-\Theta$ - /Sapphire, $w=436 \mu \mathrm{m}$

$\mathrm{CPW}: \diamond / \mathrm{LAO}, \mathrm{w}=6 \mu \mathrm{m}, \mathrm{g}=30 \mu \mathrm{m}$;

/Sapphire, $\mathrm{w}=18 \mu \mathrm{m}, \mathrm{g}=30 \mu \mathrm{m}$;

CS: $\quad \nabla / \mathrm{LAO}, \mathrm{w}=70 \mu \mathrm{m}, \mathrm{g}=30 \mu \mathrm{m}$;

$-\nabla^{-}$/Sapphire, $\mathrm{w}=310 \mu \mathrm{m}, \mathrm{g}=30 \mu \mathrm{m}$. 
Fig. 5: Tunability of the uni-planar TL versus gap width g. Conductors and dielectrics are ideal. Substrate: sapphire, $\varepsilon_{\mathrm{r}}=10, \mathrm{~h}=500 \mu \mathrm{m}$; Ferroelectric film: $500<\varepsilon_{\mathrm{rf}}<700, \mathrm{~h}_{\mathrm{f}}$ $=0.5 \mu \mathrm{m} .5 \mu \mathrm{m}<\mathrm{g}<100 \mu \mathrm{m}$.

$\mathrm{CPW}: \mathrm{w}=18 \mu \mathrm{m}$;

$-\nabla-\quad \mathrm{CS}: \mathrm{w}=310 \mu \mathrm{m}$.

Fig. 6: Variation of the insertion losses of TL at $10 \mathrm{GHz}$ as a function of the loss tangent $\tan \delta_{\mathrm{f}}$ of the ferroelectric film. Conductors: $\sigma=3,8 \times 10^{7} \mathrm{~S} / \mathrm{m}$ (Aluminium), $\mathrm{t}=2 \mu \mathrm{m}$; Substrate: sapphire, $\varepsilon_{\mathrm{r}}=10, \tan \delta=10^{-4}, \mathrm{~h}=500 \mu \mathrm{m}$; Ferroelectric film: $\varepsilon_{\mathrm{rf}}=700$, $10^{-4}<\tan \delta_{\mathrm{f}}<5 \times 10^{-1}, \mathrm{~h}_{\mathrm{f}}=0.5 \mu \mathrm{m}$. The values of $(\mathrm{w}, \mathrm{g})$ are those given in Fig.2.

$-\Theta-\mathrm{MS}$

$\Leftrightarrow-\mathrm{CPW}$

$-\nabla^{-}$CS.

Fig. 7: Contribution of different losses for each TL at $10 \mathrm{GHz}$. Conductors: $\sigma=3,8 \times 10^{7}$ (Aluminium), $\mathrm{t}=2 \mu \mathrm{m}$; Substrate: sapphire, $\varepsilon_{\mathrm{r}}=10, \tan \delta=10^{-4}, \mathrm{~h}=500 \mu \mathrm{m}$; Ferroelectric film: $\varepsilon_{\mathrm{rf}}=700, \tan \delta_{\mathrm{f}}=10^{-3}\left(\right.$ Fig.8-(a)) and $\tan \delta_{\mathrm{f}}=10^{-1}\left(\right.$ Fig.8-(b)), $\mathrm{h}_{\mathrm{f}}$ $=0.5 \mu \mathrm{m} .(\mathrm{w}, \mathrm{g})$ for lines are those given in Fig.2.

- Conductor loss;

Ferroelectric loss;

Dielectrics loss in the substrate. 
Fig. 8: Variation of the insertion losses of $\mathrm{TL}$ at $10 \mathrm{GHz}$ as a function of the gap width $\mathrm{g}$. Conductors: $\sigma=3,8 \times 10^{7}$ (Aluminium), $\mathrm{t}=2 \mu \mathrm{m}$; Substrate: sapphire, $\varepsilon_{\mathrm{r}}=10, \tan \delta=$ $10^{-4}, \mathrm{~h}=500 \mu \mathrm{m}$; Ferroelectric film: $\varepsilon_{\mathrm{rf}}=700, \tan \delta_{\mathrm{f}}=5 \times 10^{-2}, \mathrm{~h}_{\mathrm{f}}=0.5 \mu \mathrm{m} .5 \mu \mathrm{m}<\mathrm{g}$ $<30 \mu \mathrm{m}$.

$\vartheta^{-} \mathrm{CPW}: \mathrm{w}=18 \mu \mathrm{m}$

$-\nabla-\mathrm{CS}: \mathrm{w}=310 \mu \mathrm{m}$

Fig. 9: Variation of the figure of merit of $\mathrm{TL}$ at $10 \mathrm{GHz}$ as a function of the gap width $\mathrm{g}$. The figure of merit of MS lines has been included for comparison purposes. Conductors: $\sigma=3,8 \times 10^{7}$ (Aluminium), $\mathrm{t}=2 \mu \mathrm{m}$; Substrate: sapphire, $\varepsilon_{\mathrm{r}}=10, \tan \delta=$ $10^{-4}, \mathrm{~h}=500 \mu \mathrm{m} ;$ Ferroelectric film: $\varepsilon_{\mathrm{rf}}=700, \tan \delta_{\mathrm{f}}=5 \times 10^{-2}, \mathrm{~h}_{\mathrm{f}}=0.5 \mu \mathrm{m} .5 \mu \mathrm{m}<\mathrm{g}$ $<30 \mu \mathrm{m}$.

$-\Theta-M S: w=436 \mu \mathrm{m}$

$\mathrm{CPW}: \mathrm{w}=18 \mu \mathrm{m}$;

$-\nabla-\quad \mathrm{CS}: \mathrm{w}=310 \mu \mathrm{m}$. 


\section{FIGURES}

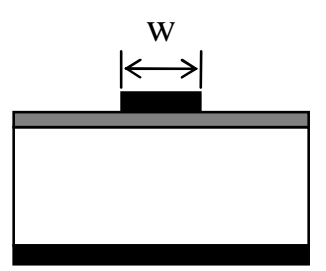

(a) MS

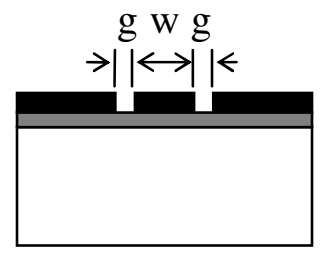

(b) CPW

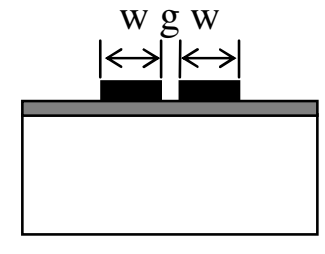

(c) $\mathbf{C S}$

Fig.1

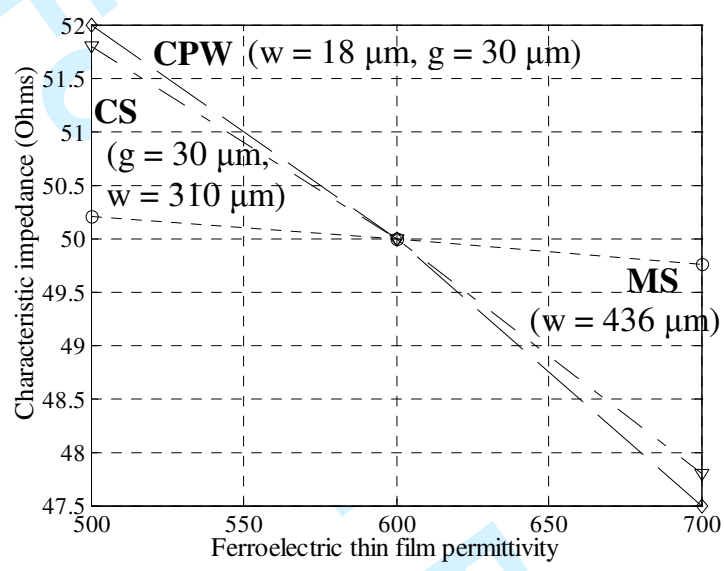

Fig.2-(a)

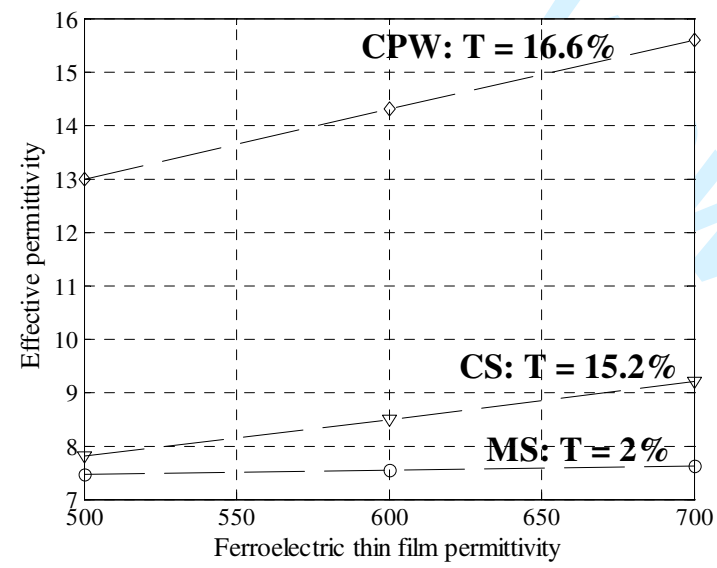

Fig.2-(b) 


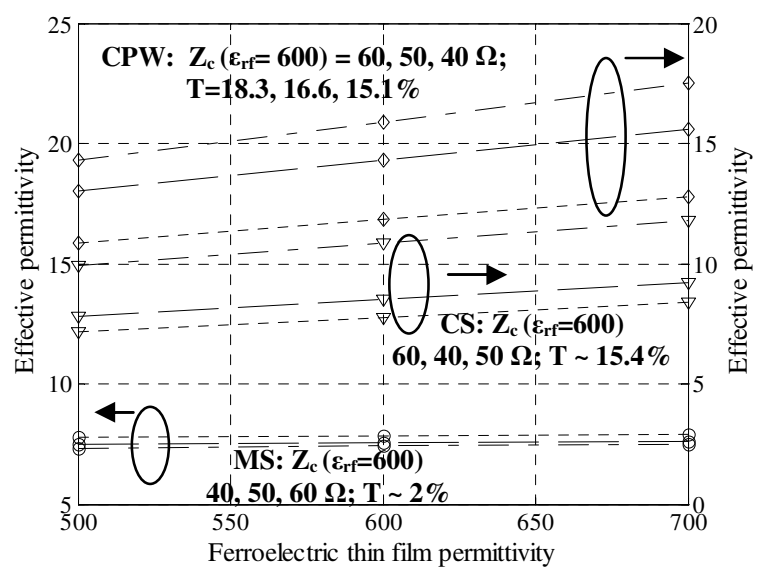

Fig.3

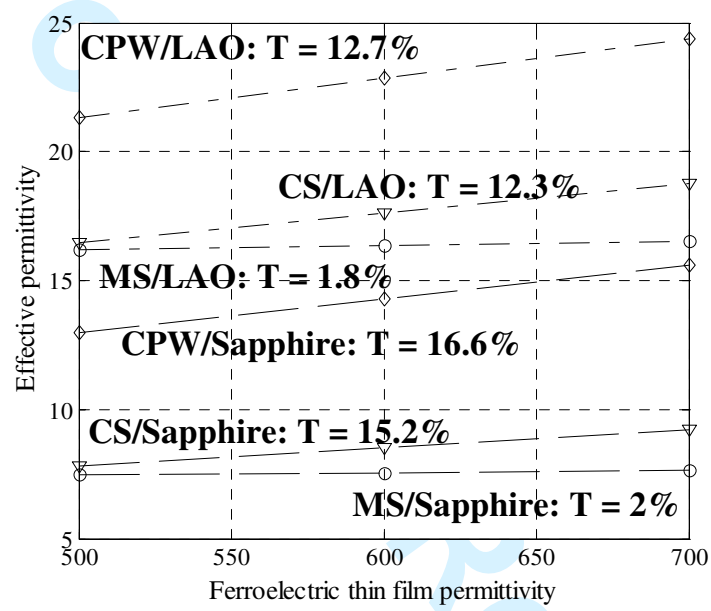

Fig.4

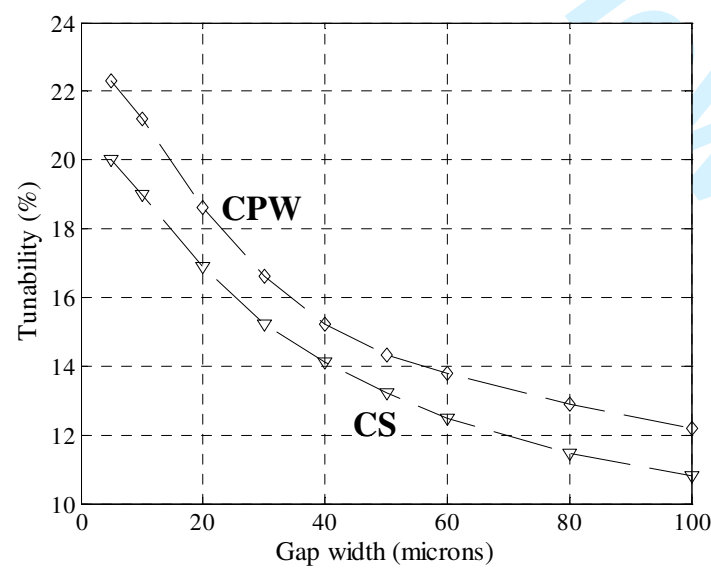

Fig.5 


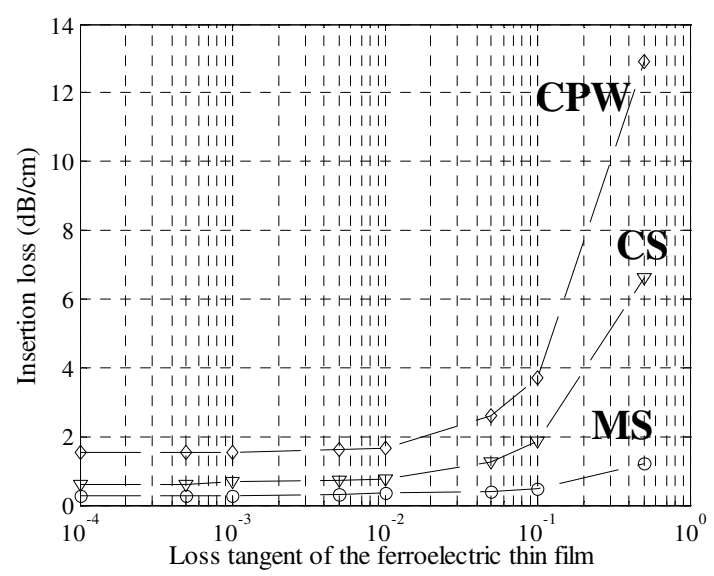

Fig.6

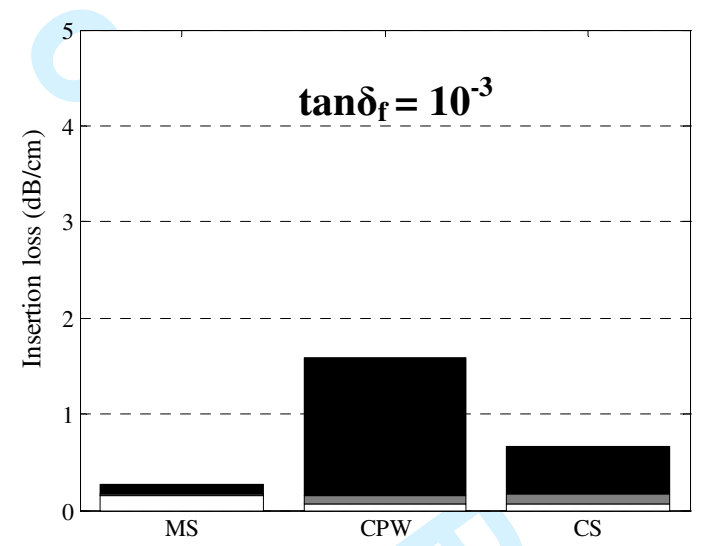

Fig.7-(a)

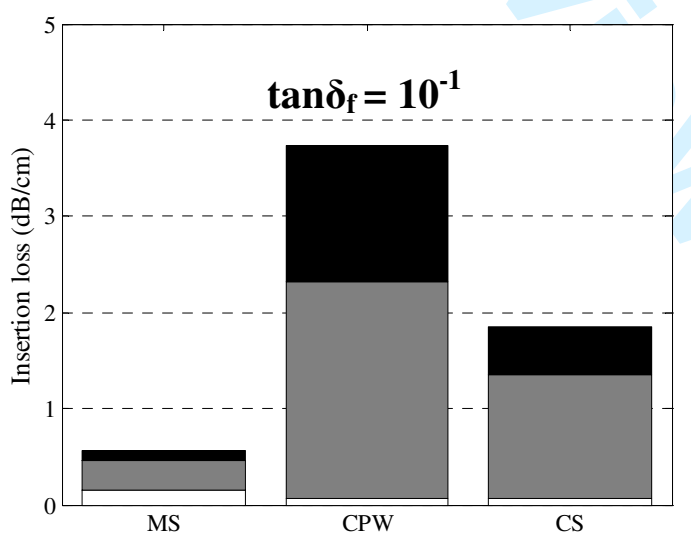

Fig.7-(b) 


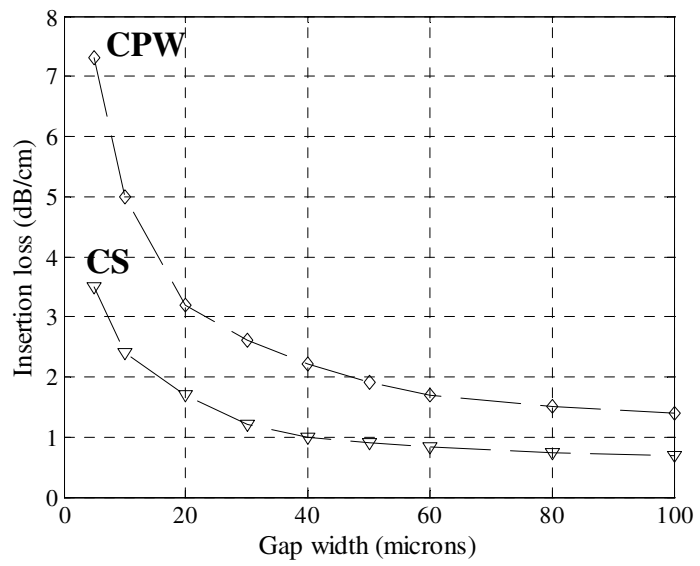

Fig.8

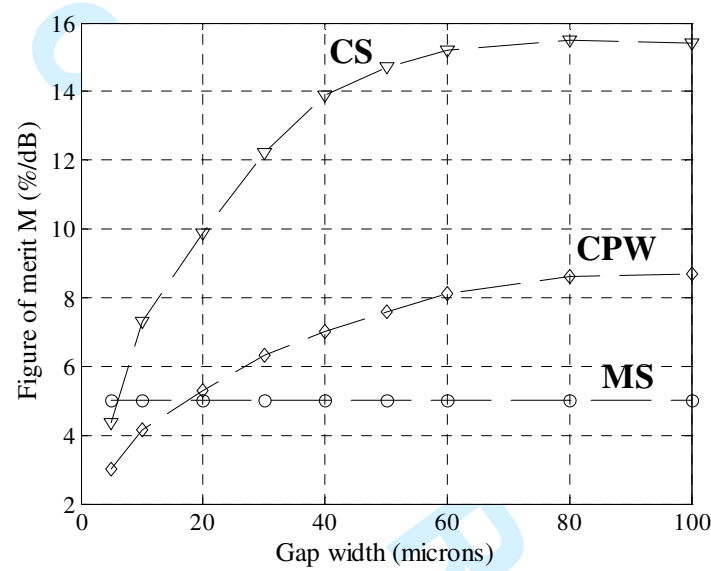

Fig.9 